\title{
A POLÍTICA EDUCACIONAL PAULISTA: CONTROVÉRSIAS EM TORNO DOS CONCEITOS DE DESCENTRALIZAÇÃO E AUTONOMIA - 1983 A 1999
}

\author{
Ângela Maria Martins
}

RESUMO: Este texto avalia as diretrizes da política educacional da Secretaria de Estado da Educação que outorgaram autonomia pedagógica, administrativa e financeira à rede de escolas. Para análise do discurso oficial foram considerados os principais documentos que justificam as opções políticas na formulação da agenda da Secretaria e que explicitaram suas metas para o período de 1983/1999, bem como as medidas legais que regulamentaram o processo de concessão de autonomia e descentralização à rede de ensino.

Palavras-chave: Avaliação de política educacional. Gestão. Autonomia. Descentralização.

Educational policies in the State of São Paulo: CONTROVERSIES AROUND THE CONCEPTS OF DECENTRALIZATION AND AUTONOMY - 1983-1999

ABSTRACT: Among the educational policies from the Department of Education of the State of São Paulo, this paper assesses the guidelines that gave pedagogical, administrative and financial autonomy to the network of schools. The official discourse is analyzed on the base of both the main documents that justified the political options to formulate the agenda of the Department and clarified its goals, between 1983 and 1999, and the legal measures taken to regulate the process that granted autonomy and decentralization to that schooling network.

Key words: Assessment of educational policies. Administration. Autonomy. Decentralization.

Socióloga, doutora em Educação e pesquisadora da Fundação Carlos Chagas.

E-mail: amartins@fcc.org.br

Educ. Soc., Campinas, vol. 24, n. 83, p. 527-549, agosto 2003

Disponível em <http://www.cedes.unicamp.br> 


\section{O período de 1983/1994}

tema da autonomia é antigo na história da educação paulista. Já em 1932, o Manifesto dos Pioneiros da Educação Nova citava três vezes a palavra autonomia “(...) apenas para indicar a conveniência de que, além das verbas orçamentárias, fosse constituído um fundo especial destinado exclusivamente a atender empreendimentos educacionais que assim ficariam a salvo de injunções estranhas à questão educacional" (Azanha, 1993, p. 37). De acordo com os pressupostos filosóficos expressos no Manifesto, o Decreto n. 5.884/1933 reorganizou todo o sistema de ensino paulista, instaurando a organização administrativo-pedagógica das escolas rurais isoladas e das escolas de formação do professor primário e secundário. Um de seus artigos afirmava que o professor deveria ter "autonomia didática dentro das normas técnicas gerais indicadas pela pedagogia contemporânea" (idem, ibid.).

Recentemente, no entanto, o tema conquistou relevância na agenda formulada pela política educacional do estado de São Paulo a partir de 1983, transformando-se em eixo de suas diretrizes materializadas em medidas normativas e legais, sob a justificativa de ser o principal instrumento de gestão democrática da escola pública. Em âmbito nacional, a eleição de governos estaduais e municipais de oposição ao regime militar em 1982 e 1985, respectivamente, consagrou o lema da descentralização do sistema de ensino e da autonomia da escola como mote político dos discursos que fundamentariam as plataformas de candidatos e programas de governo. Em âmbito estadual, a agenda da Secretaria de Educação explicitava suas diretrizes políticas em torno da seguinte pauta: democratizar a gestão da escola pública; formar cidadãos críticos e participantes; promover ampla reforma administrativa para racionalizar recursos e acabar com o excesso de burocracia; melhorar a qualidade do ensino ofertado, sem deixar de atender à demanda; propiciar melhores condições de trabalho aos professores com remuneração justa; descentralizar recursos e outorgar autonomia administrativa às instâncias intermediárias do próprio sistema estadual e à esfera municipal.

Em consonância com os argumentos oriundos do mundo acadêmico e/ou sindical e na esteira das tendências internacionais, o discurso da política educacional paulista destacava a importância dos processos de descentralização em nível político, salientando a neces- 
sidade de se democratizar e ampliar a participação dos usuários da rede pública de ensino por meio do fortalecimento do poder local. Com relação às questões de ordem pedagógica, sublinhava a importância de sua participação na elaboração de planos, programas e projetos educacionais; no nível econômico, ressaltava a possibilidade de se otimizar os recursos financeiros e, no nível administrativo, a conquista de agilidade no fluxo burocrático com a diminuição de níveis hierárquicos de poder.

Para dar início ao processo de desmonte da herança burocrático-administrativa centralizada, instaurada por anos de política autoritária, o governo recém-eleito promoveu, em 1983, dois grandes eventos: o Fórum de Educação do Estado de São Paulo, ao mesmo tempo em que chegava às Delegacias de Ensino e unidades escolares o Documento Preliminar para Reorientação das Atividades da SE do Estado de São Paulo, denominado Documento n. 1. A leitura e a discussão desse documento por toda a rede de ensino do estado, bem como a reprodução do Fórum de Educação em algumas regióes do estado, desencadearam um processo de distensão nas relaçôes entre o conjunto de escolas, os profissionais do ensino e o poder executivo. De modo geral, os resultados das referidas discussões apontavam como agravante para a implementação das políticas na área a ausência de diretrizes coerentes, capazes de superar a situação dicotômica posta pela tensão entre expansão de oportunidades e a qualidade do ensino ofertado.

A concepção ampla de participação democrática refletia, antes de mais nada, o momento específico de instauração de governos estaduais de oposição que dialogavam com os setores democráticos mais que os anteriores. Em âmbito nacional, a sociedade civil pressionava para que a transição do regime militar para um regime democrático ampliasse as reformas legais e normativas que regulamentavam o Estado brasileiro. Em âmbito estadual, a política educacional iniciada em 1983 representava, de alguma forma, a efetivação de mudanças reivindicadas por setores acadêmicos e sindicais, ainda que algumas tímidas e, outras, controvertidas. O magistério, como categoria profissional das mais organizadas no estado de São Paulo, vinha reivindicando reformas significativas nos assuntos referentes à cultura e educação: liberdade de expressão, fim da censura, maiores subsídios à pesquisa e ao ensino, aumentos salariais, melhoria nas condições de trabalho e descentralização do poder de Estado, diminuindo seus níveis hierárquicos e burocráticos. 
O Documento n. 1 incorporou essa pauta e acrescentou, ainda, a necessidade de a Secretaria de Estado da Educação instaurar um amplo processo de discussão que considerasse a escola pública como espaço legítimo para construção do conhecimento, a partir de um projeto pedagógico que respeitasse a heterogeneidade da clientela escolar. Para isso, apontava alguns caminhos: a reformulação do currículo e a transformação das instâncias intermediárias do poder; reformas no Estatuto do Magistério, no Regimento Interno das escolas de $1^{\circ}$ e $2^{\circ}$ graus e no Conselho de Escola. Outro agravante apontado no Documento n. 1 dizia respeito à quantidade irrisória de recursos destinados à rede pública e ao mau emprego desses recursos. Enfatizava, ainda, a autonomia como elemento condicionante para a real conquista de uma escola com qualidade. Os apelos democráticos, no entanto, esbarravam na cultura fortemente enraizada no desenho institucional da política da área.

Azanha, ao criticar os intervenientes conservadores que recrudesciam ante as propostas de democratização do aparato burocráticoadministrativo, sublinhava que

(...) em nome de uma alegada necessidade de disciplinar 'enquanto' as escolas não estiverem em condições de se organizar, o que temos não é a sadia diversidade do que é mesmo desigual, mas a aplastante uniformidade que pretende eliminar a possibilidade do erro, e que de fato elimina a responsabilidade. Não pode ser responsável perante o seu próprio trabalho quem não tem nenhuma autonomia de decisão. (Azanha, 1987, p. 127)

Ao que tudo indica, a defesa da autonomia da escola não tem ido além da superfície do tema, pois

no universo verbal da legislação e dos pareceres dos Conselhos de Educação, toda a questão parece se resumir em ter-se um regimento próprio no qual figure com destaque um 'Conselho de Escola' com ampla representatividade e atribuições deliberativas. Porém, ainda que a autonomia da escola possa ou deva abranger esses aspectos é claro que o assunto não deve nem pode se esgotar nisso. (Azanha, 1987, p. 143) ${ }^{2}$

Até 1985, a defesa da descentralização do sistema de ensino consolidou-se como eixo na política educacional sem que houvesse clareza, porém, sobre os procedimentos administrativos, financeiros e pedagógicos que lhe dariam concretude. ${ }^{3}$ Estudos encomendados a instituições de pesquisa ratificavam críticas acadêmicas que salientavam o gigantismo da estrutura, a sobreposição de funções dos 
órgãos centrais, a ineficiência dos procedimentos administrativos e financeiros da organização, enfim, desvios das atividades-fim para as atividades-meio do sistema (São Paulo, 1984). Após 1985, no entanto, a Secretaria de Estado da Educação abandonou o discurso genérico e iniciou amplo processo de concretização de medidas de descentralização administrativa e financeira, tais como os programas de merenda e material escolar, municipalizando esses serviços por meio de parcerias; transformou as Delegacias de Ensino em Unidades de Despesa, em nível de Divisão, e as Divisões Regionais em unidades orçamentárias, em nível de Departamento; e transformou, ainda, o Conselho de Escola em órgão deliberativo. ${ }^{4}$

Desse período em diante, o discurso do poder executivo estadual paulista encontraria respaldo no revigoramento do federalismo. $\mathrm{O}$ pacto da lealdade, sedimentado entre governadores e deputados federais a partir das eleições de 1982, "fortaleceu os 'chefes estaduais' diante do 'chefe da nação', 'sobretudo nos assuntos com impacto federativo"”. Em função dessa influência, os governadores conseguiram manter a "distribuição de recursos dentro da federação, permitindo-lhes construir sólidas coalizões fisiológicas de governo nos Estados" (Abrucio, 1998, p. 97). Neste sentido, descentralizar responsabilidades às instâncias regionais e locais e centralizar recursos permaneceram sendo a tônica dos governos estaduais eleitos no período pós-1982, independentemente do fato de a Constituiçãao de 1988 ter redistribuído a tributação, beneficiando, em princípio, estados e municípios.

Em análise realizada sobre a fragilidade dos municípios na prática da negociação política no âmbito estadual, Costa \& Oliveira (1998) ressaltam que, após a Constituição, os "estados mais ricos foram proporcionalmente mais bem aquinhoados". Esse fortalecimento financeiro, no entanto, não mudou a dependência de pequenos e médios municípios quanto aos recursos estaduais. Efetivamente, "a gradual independência dos municípios em relação ao executivo estadual (poderia ocorrer) apenas mediante o aumento de arrecadação de recursos próprios aos municípios, prática ainda bastante evitada pelos prefeitos" (Costa \&"Oliveira, 1998, p. 126). Com efeito, o período entre 1983-1995 foi fortemente marcado pelo aumento do poder de barganha na esfera estadual com a criação de novos municípios, embora esta não seja prerrogativa dos governadores de estado. Porém, incentivando grupos ligados a deputados estaduais com interesses emancipacionistas, a maioria dos 
governadores, no período em pauta, conseguiu negociar a criação de municípios pelas Assembléias Legislativas de seus estados (Abrucio, 1998). ${ }^{5}$

Em São Paulo, a despeito de descontinuidades administrativas e redirecionamentos políticos ocorridos no âmbito da gestão da Secretaria de Estado da Educação, todos os programas e projetos desenvolvidos de 1983 a 1994, visando à descentralização baseada em medidas administrativo-políticas ${ }^{6}$ resguardaram a esfera executiva estadual como instância articuladora dos recursos físicos e humanos. $^{7}$ Esse processo se consolidou por meio da interiorização da política partidária, a partir de 1986, com a eleição do então governador Orestes Quércia. Desse período em diante, as políticas clientelistas foram consolidadas num quadro favorável à expansão do PMDB interiorano, concomitantemente a um processo de marginalização do partido do governador na própria capital, o que possibilitou o vácuo necessário para o crescimento do PSDB e do PT como partidos representantes do eleitorado de centro-esquerda na cidade de São Paulo.

Costa \& Oliveira (1998), ao analisarem o processo de interiorização da política paulista nos governos Quércia e Fleury, ${ }^{8}$ discutem a superioridade numérica de deputados eleitos com base eleitoral no interior e na Grande São Paulo, fato que proporcionou um reforço das práticas clientelistas nas relações entre o executivo e a sua bancada parlamentar, "já que a moeda de troca para os deputados dos municípios pequenos e médios é, basicamente, a realização de obras e distribuição de cargos públicos nas áreas em que concentra a sua votação" (Costa \& Oliveira, 1998, p. 124). Ao se analisar os dados relativos ao impacto da distribuição de recursos tributários em cidades de pequeno e médio portes nesse período, verifica-se que a impossibilidade de esses municípios arcarem com o ônus de investimentos de maior porte em infra-estrutura os colocou na dependência do poder executivo estadual, garantindo ao governo uma base de apoio aos seus projetos de $80 \%$ de deputados do interior.

Dessa forma, os programas descentralizadores para a rede de ensino estadual paulista, consolidados sobretudo a partir de 1986, foram implementados nesse contexto de negociaçôes nem sempre baseadas na política programática - aquela que se reveste de caráter mais universal - ou na barganha alocativa setorial - a partir da qual interesses e necessidades particulares de uma sociedade são atendidos. Ao que tudo indica, a relação estabelecida entre executivo/ 
legislativo no âmbito estadual, historicamente vem se fundamentando muito mais no padrão interativo clientelista, a partir do qual a destinação de recursos públicos é arbitrariamente dirigida a determinados setores da população e/ou a segmentos da própria burocracia de escalão, que se constituem como a base de apoio eleitoral e de sustentação das medidas de governo.

O Programa de Municipalização de Educação do Estado de São Paulo - Decreto n. 30.375/89 - assinado pelo então governador Orestes Quércia, por exemplo, foi apresentado como possibilidade de superação do quadro de seletividade e excludência da escola pública. No entanto, o Programa, operacionalizado via convênio, aprofundou os laços clientelistas construídos ao longo da história político-administrativa do estado. Certos aspectos do Programa eram ambíguos com relação à transparência necessária para situações de parceria. Temas tais como apoio a eventos escolares, assistência ao aluno e integração do currículo à realidade da escola, a natureza das atribuições da Comissão de Educação do Município e a ausência de explicitação dos critérios sobre quantidade dos recursos financeiros conveniados e das prioridades estabelecidas para sua aplicação, abriam todos os flancos para que um amplo campo de relações clientelistas continuasse a traçar os difíceis caminhos para a conquista das autonomias locais (Martins \& Alves, 1990).

A partir da implementação do Decreto n. 30.375/89, iniciava-se nova fase de relacionamento político-administrativo entre a Secretaria de Estado da Educação, as Secretarias Municipais, as Delegacias e Divisōes Regionais de Ensino. O processo de repasses de recursos aos municípios para merendas, transporte ou reforma e construção da rede física, iniciado nos anos de 1980 e consolidado nos anos de 1990, sofreu impactos diferentes de acordo com as características socioeconômico-demográficas das regiôes, das prioridades nas políticas públicas implementadas pelas instâncias municipais e dos acertos político-partidários. Entre os programas e/ou projetos pedagógicos implementados pela Secretaria de Estado da Educação que possibilitaram a visibilidade sobre a consolidação desses interesses conjunturais, clientelistas e/ou fisiológicos, em função da escassa solidez e ausência de transparência nos mecanismos que norteiam as relações entre as diferentes esferas de poder, pode-se citar o Programa de Formação Integral da Criança (PROFIC) como exemplo. Implantado em 1986, previa a permanência de crianças carentes em período integral nas escolas conveniadas com 
prefeituras e outras secretarias e/ou equipamentos de atendimento do setor social, todos coordenados pela Educação. ${ }^{9}$

No âmbito das inovações pedagógicas, medidas como o Ciclo Básico, a Jornada Única, o Centro de Formação do Magistério (CEFAM) e o Programa de Antecipação da Escolaridade expressavam diretrizes de mudança em face da necessidade de atender aos problemas postos para o ensino e a aprendizagem. Entre meados dos anos de 1980 e início dos anos de 1990 ocorreu, também, a reformulação do currículo da rede pública estadual paulista. Para tornar mais ágil a implantação e implementação das medidas pedagógicas, foram criadas as Oficinas Pedagógicas, alocadas nas Delegacias de Ensino, com o objetivo de desconcentrar as ações de capacitação continuada para essas Delegacias de Ensino. O processo de divulgação e discussão da reformulação curricular foi permeado de dificuldades e intervenientes burocráticos que, de modo geral, apareciam analisados nos documentos oficiais como entraves postos por uma organização complexa, que não prestava contas de seu próprio desempenho. Imputava-se, invariavelmente, às Divisões Regionais de Ensino e às Delegacias de Ensino, o estrangulamento no fluxo de informações para a rede de escolas, dificultando aos órgãos centrais uma intervenção efetiva que alterasse as práticas de sala de aula, avaliadas como conservadoras.

Em 1992, ampliou-se a idéia de outorga de autonomia à escola, com a implementação do Programa de Reforma da Escola Pública, denominado Escola-Padrão. O foco político da descentralização deslocou sua prioridade dos órgãos intermediários para a própria unidade escolar, com base em novos procedimentos administrativos, financeiros e pedagógicos: a caixa de custeio, o contrato de gestão e $o$ plano diretor (São Paulo, 1992b). Ao processo de desconcentração das ações de capacitação, iniciado com as Oficinas Pedagógicas, seguiu-se um processo de descentralização, baseado na ampliação das funções de coordenação e execução das antigas Divisões Regionais de Ensino e das próprias Oficinas Pedagógicas. O Programa de Reforma da Escola-Padrão foi desativado a partir de 1995.

No entanto, alguns dos conceitos que norteavam o novo conjunto normativo, com implicações no planejamento orçamentário, pedagógico e administrativo das escolas, foram consolidados, com particular destaque para a caixa de custeio e o plano diretor, pois ambos os procedimentos de planejamento são peças fundamentais no desenvolvimento e exercício da autonomia escolar. A partir daí, 
consagrou-se o uso equivocado do conceito de autonomia, compreendido como um processo de outorga de normas oficiais e medidas legais, e visto como mais um entre os muitos mecanismos de descentralização de medidas administrativas.

Com relação à avaliação, entre 1983 e 1987 os documentos oficiais registravam, sobretudo, a preocupação em questionar o tradicionalismo das escolas na adoção dos procedimentos avaliativos de alunos, tema esse amplamente discutido em seminários organizados pela Coordenadoria de Estudos e Normas Pedagógicas destinados a supervisores e diretores de escola, principalmente (São Paulo, 1984b; 1988). Naquele momento, a preocupação maior da Secretaria de Estado da Educação era a de sensibilizá-los com relação à necessidade de mudarem seus procedimentos de avaliação, tendo em vista os altos índices de repetência e evasão da rede de ensino, preocupação essa, aliás, que expressava o pensamento predominante nos fóruns de educação, nos debates acadêmicos e até mesmo no âmbito de estudos realizados com o intuito de subsidiar o Ministério da Educação no redirecionamento de suas políticas de atendimento às demandas.

Nesse período, muitos pesquisadores posicionaram-se com relação aos índices de repetência da rede pública de ensino, enfatizando seu caráter excludente, provocando no sistema o que alguns desses estudiosos denominaram de pedagogia da repetência (Ribeiro, 1991; Fletcher \& Castro, 1993). Alguns estudos apontavam a necessidade de se introduzir modificaçôes em procedimentos estatísticos adotados pelo MEC ao diagnosticar o fluxo de alunos, propondo para tanto a adoção de uma nova metodologia denominada Profluxo. Os resultados obtidos nesses diagnósticos ressaltavam alguns aspectos que contrariavam pesquisas realizadas na área acadêmica, quais sejam: as taxas de evasão eram muito baixas; o sistema de ensino atendia até $95 \%$ da população em idade escolar; o índice de alunos que entravam atrasados no sistema de ensino era inexpressivo e a questão central se resumia à repetência, provocada pela má qualidade do ensino. A estruturação e consolidação de um sistema nacional de avaliação a partir de meados dos anos de 1990 em âmbito nacional constituíram-se, dessa forma, no arcabouço de um intenso movimento de idéias e debates que, antes de mais nada, questionava a cultura avaliativa da rede de escolas, pois ao configurar um padrão de repetência excluía um número expressivo de crianças e jovens da possibilidade de concluir a escolaridade regular, 
promovendo estrangulamentos no fluxo do sistema e onerando, sobremaneira, os cofres públicos. Neste sentido, ao longo dos anos de 1980, semeava-se o terreno em que se desenvolveria, já a partir de seus últimos anos, o cenário para que as propostas de avaliação do desempenho da rede de escolas se consolidassem.

Ao realizar um levantamento sobre os estudos avaliativos de desempenho escolar desenvolvidos no estado de São Paulo, Gatti (1996) destaca aqueles implementados a partir de 1988 e que podem ser associados à possível constituição de um Sistema Nacional de Avaliação: a) o Projeto de Avaliação de Desempenho de alunos de $3^{\mathrm{a}}$ série do $2^{\circ}$ grau, realizada em 1990 , visando ao levantamento de informaçóes sobre alunos da rede publica e privada, para melhor compreensão dos problemas que afetavam esse nível de escolaridade; b) o primeiro movimento que realmente buscava pensar num sistema de avaliação em termos de Secretaria da Educação de São Paulo, realizado em 1992, vinculado a uma política específica - o Programa da Escola-Padrão, que teve vários desdobramentos; c) o sistema mais amplo de avaliação que deveria abranger todos os tipos de escola no estado de São Paulo e incluir crianças de $4^{\mathrm{a}}$ a $8^{\mathrm{a}}$ série, desenvolvido a partir de 1994; d) o Projeto de Avaliação de Impacto do Ciclo Básico e da Jornada Única na Área Metropolitana de São Paulo, que, no período de 1992/1994, vinha sendo desenvolvido nas escolas estaduais, com caráter de verdadeira pesquisa avaliativa.

Efetivamente, em 1989, a Secretaria de Estado da Educação de São Paulo, com recursos do governo do estado e financiamento do Banco Mundial, iniciou o Projeto Inovaçôes no Ensino Básico (IEB) (São Paulo, 1989). O referido projeto injetou nas escolas da Regiāo Metropolitana recursos que se traduziram em aumento dos materiais didático-pedagógicos, merenda de melhor qualidade e oportunidades de aperfeiçoamento para os profissionais da educação. Fazia parte do financiamento concedido, porém, a avaliação de todas essas medidas. Sem se constituir ainda em sistema de avaliação externa sobre o desempenho da rede de ensino paulista, esse projeto - que adquiriu caráter de pesquisa avaliativa - restringia-se a 60 escolas e apresentava as seguintes características: a realização de testes de rendimento escolar por três anos seguidos, avaliando alunos matriculados em escolas com Jornada Única, e alunos matriculados em escolas sem Jornada Única, em escolas que se tornaram padrão em 1992 e em escolas que se tornaram padrão em 1993 (São Paulo, 1997). 
Os testes examinaram questōes de língua, leitura e Matemática. Além desse estudo longitudinal, houve a realização de um estudo antropológico em quatro escolas, envolvendo observaçōes sobre as práticas escolares e sobre as questōes socioeconômicas das famílias dos alunos, permitindo "que se (tivesse) uma compreensão profunda do que se passava no cotidiano das escolas e no desenvolvimento cognitivo das crianças (...)" (Gatti, 1996, p. 26). Nesse mesmo período - início dos anos de 1990 - a Secretaria de Estado da Educação tomou a iniciativa de dar continuidade aos estudos preliminares desenvolvidos até então sob estímulo do MEC, avaliando o Programa de Reforma da Escola-Padrão. Essa avaliação foi realizada em 306 escolas, onde o Programa estava inicialmente implantado, em Língua Portuguesa, Redação, Matemática, Ciências, História e Geografia. Em 1994, porém, sua continuidade incluiu as escolas que ainda não haviam se transformado em escolas-padrão, na tentativa de desenvolver um "sistema mais amplo de avaliação do sistema (...)" (Gatti, 1996, p. 25). A ampla divulgação dos resultados desse processo de avaliação externa sobre o desempenho das escolas ocorreu num momento histórico de mudanças políticas, a partir de 1995.

\section{O período de 1995/1999 $9^{10}$}

Como se discutiu anteriormente, a agenda política implementada a partir de meados dos anos de 1980 na educação paulista derrapou até meados dos anos de 1990 no modelo de gestão de Estado intrinsecamente ligado a mecanismos centralizadores. A ruptura desse modelo se consolidou a partir daí, com a vitória do ideário que defendia um projeto de modernização administrativa para a área. $\mathrm{Na}$ história política brasileira, a tensão entre centralização/descentralização sempre esteve presente desde o momento de constituição da Nação, expressando emblematicamente a questão federativa. ${ }^{11}$

Em âmbito estadual, a legitimidade conquistada nas eleições de 1994 ocorreu na esteira das propostas gerais de reforma do Estado, centradas em novos paradigmas de gestão com vistas a reorientar suas funçōes e estrutura, apresentando como metas a serem cumpridas: a necessidade de privatização das empresas estatais ou a ampliação das parcerias com setores privados lucrativos ou não-lucrativos na prestação de serviços, a diminuição dos quadros burocráticos estaduais e a implementação de reformas nos sistemas de saúde e educação. A elei- 
ção do governador Mário Covas consolidou nova agenda na implementação das políticas públicas. As administrações estaduais do período histórico imediatamente anterior (1984-1994) ainda utilizavam com algumas restriçôes certos temas polêmicos e refutados pelos setores mais progressistas da educação: municipalização do ensino; novas formas de gerenciamento da educação para aumentar a produtividade, a qualidade e a eficiência dos serviços prestados; avaliação do sistema de ensino; instauração de ciclos e classes de aceleração, entre outros, embora o balão de ensaio estivesse lançado.

A plataforma política apresentada por Covas para sua reeleição em 1998 apenas indicava o aprofundamento das medidas anteriores. A credibilidade que o alçou a um segundo mandato estava intrinsecamente relacionada à idéia de austeridade na administração das contas do estado e, segundo a imprensa, na parcimônia com que conduziu a realização de obras sem comprometer os cofres públicos. ${ }^{12}$ Nesse cenário, é possível analisar o redirecionamento do discurso e das medidas políticas da área. Partindo de justificativa exaustivamente utilizada por governos anteriores, as Diretrizes Educacionais para o Estado de São Paulo (1995/1998) sinalizavam, também, a defesa da modernização da educação. $\mathrm{O}$ discurso sublinhava que a nova perspectiva para a educação paulista dizia respeito, na realidade, à superação da velha dicotomia quantidade versus qualidade, pois "(...) Uma meta, que é mais ampla e que não depende somente da Secretaria, mas de política educacional do Estado, é a que temos da descentralização" (Silva, 1996, p. 8).

Para alcançar essa meta, várias medidas foram implementadas, dentre as quais se destacam: as que sublinhavam a necessidade de fortalecimento da autonomia administrativo-pedagógica das Delegacias de Ensino e unidades escolares, delegando-lhes a responsabilidade de acompanhar o cumprimento das metas estabelecidas pela administração central com relação à diminuição dos índices de repetência de alunos; as medidas legais que salientavam o papel da unidade escolar pelo seu próprio desempenho; o Programa de Reorganização das Escolas da Rede Pública Estadual, implantado em 1996; as mudanças curriculares e as medidas de correção do fluxo escolar; as medidas de reorientação nos procedimentos burocrático-administrativos e financeiros entre os órgãos centrais, regionais, unidades escolares e instâncias municipais; as medidas que salientavam a necessidade de participação da sociedade no processo de recuperação e melhoria da qualidade do ensino público paulista, instituindo 
ação conjunta entre a APM, o setor privado e demais entidades da sociedade civil. É importante, ainda, ressaltar o conceito de autonomia escolar definido nos documentos oficiais, segundo o qual “(...) Cabe às escolas definir: o tratamento a ser dado aos conteúdos curriculares; os métodos de ensino empregados; o uso mais adequado do tempo e do espaço físico; e gerenciar os recursos humanos e materiais que recebem para realizar seu próprio projeto" (Silva, 1999, p. 173).

No entanto, dentre todas as medidas de descentralização, merece destaque o Decreto n. 40.673/96, posteriormente alterado pelo Decreto n. 40.889/96, que instituiu o Programa de Ação de Parceria Educacional Estado-Município, para atendimento ao ensino fundamental, consolidando o processo de municipalização iniciado já em 1989, com o Decreto n. 30.375/89. O instrumento administrativo criado para viabilizar o Programa de Ação de Parceria Educacional Estado-Município foi um Termo de Convênio, do qual faziam parte um Plano de Trabalho do município com objetivos e metas, um Plano de Aplicação dos Recursos e um Cronograma de Desembolso Financeiro. Na assinatura dos dois primeiros eventos de municipalização, apenas 46 municípios apresentaram todas as condiçôes legais e financeiras para aderir à parceria (São Paulo, 2002). ${ }^{13}$

Antes de consolidar o processo de municipalização, a Secretaria de Estado da Educação havia elaborado, por meio da Fundação de Desenvolvimento Administrativo (FUNDAP), um documento de implantação da medida. Nele, destacava a necessidade de se estabelecer uma ação compartilhada entre a Secretaria de Estado da Educação e os municípios para desenvolvimento, melhoria e expansão do ensino fundamental, mediante ação conjunta dos poderes executivos estadual e municipais para consolidar o processo de descentralização político-administrativa, afirmando que a secretaria tem

(...) a convicção de que a descentralização não é panacéia para resolver todos os problemas do nosso ensino público. Por outro lado, também tem a certeza de que, à medida que a máquina burocrática cresce de forma desmesurada, não é mais possível resolver, em nível central, os problemas que afligem os educadores em seus cotidianos de trabalho. A descentralização, ao permitir maior acompanhamento da escola e do trabalho de diretores e professores pelas comunidades locais, pode ser um caminho mais seguro para reduzir significativamente o alto grau de ine- 
ficiência e ineficácia das ações desencadeadoras devido à superposição de competência dos órgãos centrais e à ausência de mecanismo de controle e avaliação das ações (...). (São Paulo, 1997, p. 13)

O conjunto normativo que se seguiu ao Decreto n. 40.673/ 96 instituiu várias medidas de reorientação nos procedimentos burocrático-administrativos, cujo impacto sobre a rede de escolas ainda merece análise cuidadosa. Enfatizando a necessidade de descentralizar recursos e procedimentos administrativos, o Decreto n. 40.904, de 12 de junho de 1996, reestruturou as normas que norteariam as relações entre a Fundação para o Desenvolvimento da Educação, a Secretaria de Estado da Educação e os municípios para repasse de recursos das construções e reformas escolares. Os convênios assinados a partir daí permitiram que as prefeituras, mediante a disponibilização do terreno, tivessem acesso ao financiamento estadual para construção, gerenciada pelo próprio município. No entendimento de Silva, a secretaria havia iniciado um processo de desconcentração administrativa, "que significa, em última instância, dar maior poder às instâncias que estão mais próximas das escolas" (Silva, 1999, p. 173).

O processo de escolha para designação de professor para exercer as funções de coordenação pedagógica nas escolas da rede pública estadual e o processo de regulamentação das funções de vice-diretor das escolas pelo Plano de Carreira também merecem destaque. Analisaram-se, ainda, a alteração da nomenclatura e a reorganização das Delegacias de Ensino, objetivando tornar mais ágil seu fluxo de atendimento, "modernizar e racionalizar" a Secretaria de Estado da Educação, bem como "acelerar as medidas de descentralização para fortalecer a gestão local”. Por fim, ressaltem-se os problemas que emergiram no processo de discussão das Normas Regimentais Básicas para as Escolas Estaduais, as quais, ao lado do Plano Diretor das Escolas, constituem a possibilidade efetiva de as escolas conquistarem e exercerem sua autonomia. Em longo e conturbado processo de negociação com a categoria e as intervenções de seu sindicato, as normas tramitaram pelo órgão competente, o Conselho Estadual da Educação, sendo posteriormente promulgadas pela Secretaria de Estado da Educação. Com 8 títulos e 87 artigos, o documento definiria com precisão todos os procedimentos que normatizariam desde a concepção de gestão democrática (que deveria ser adotada pela escola) até o processo de avaliação de ensino e aprendizagem; da organização do ensino à organização administrativa. 
O espaço destinado à unidade escolar no organograma da Secretaria de Estado da Educação permite a compreensão do funcionamento e da estrutura da organização, pois a concepção político-administrativa que fundamentou o Decreto n. 7.510/76 permanece orientando seu modus operandi. Neste sentido, a escola está localizada na base do sistema tendo uma significativa estrutura burocrática sobre ela. A concepção tecnocrática prevalecente nos anos de 1970 configurou uma estrutura burocrática na instituição que, via de regra, tem priorizado o planejamento centrado na normatização racional-legal.

É interessante recordar que a concepção de planejamento tecnocrático, consolidado durante o regime militar, moldou nas políticas setoriais a busca de adequação dos serviços públicos às demandas do mundo do trabalho. Com relação às políticas educacionais, esse tema foi explorado em inúmeros trabalhos. Outros estudos já apontavam nos anos de 1980 a utilização das teorias gerais da administração de empresas e das técnicas administrativas na estruturação do planejamento do sistema de ensino visando a ampliar sua eficácia e eficiência. A mera transposição de procedimentos, técnicas e pressupostos teórico-metodológicos, das teorias gerais de administração para o âmbito da administração na educação, tem sido apontada como a prevalência de uma visão equivocada centrada em questôes técnicas: para se obter a melhoria da qualidade do ensino ministrado em escolas públicas, bastariam uma nova regulação normativa e novos procedimentos burocráticos de funcionamento do sistema.

É inegável que o momento histórico atual insiste nessa relação equivocada sob a defesa de uma mudança de paradigma na gestão das políticas da área. A agenda política implementada a partir de meados dos anos de 1980 na educação paulista - centrada no discurso da modernização e da autonomia da escola como um dos principais instrumentos para instaurar uma gestão democrática não logrou romper definitivamente a cultura político-administrativa consagrada por práticas tradicionais, apesar do projeto de modernização administrativa para a área, tema presente no discurso oficial desde a formulação do Decreto n. 7.510/76. A permanência do tema e a centralidade por ele conquistada a partir dos anos de 1980 não deixam dúvida quanto à tensão inerente na elaboração da agen- 
da para a área. As propostas recentes de modernização do sistema de ensino no âmbito estadual esbarram, permanentemente, na cultura político-administrativa sacralizada, ou seja, em relações institucionais cristalizadas na máquina pública que impedem até mesmo a perenidade dos programas.

Neste sentido, Pereira (1967) já sublinhava, nos anos de 1960, que as graves questôes advindas de intervenientes burocráticos podem estar menos relacionadas à dinâmica estabelecida por possíveis conseqüências de disfunção burocrática no seu sentido clássico, weberiano, do que à forte permanência de uma tensão constituída pela prevalência de valores tradicionais, patrimonialistas, que configuram uma cultura na área difícil de ser rompida. O campo de tensão constituído nesse processo apresenta elementos do projeto de modernização encetado desde fins dos anos de 1970 e elementos tradicionais que a eles se mesclam, potencializando, nas escolas paulistas, comportamentos de resistências, omissões, dissimulações e/ou simplesmente de adesões às orientações oficiais por meio de cumprimento ritual das ordens emanadas (Martins, 2001). ${ }^{14}$

Com base na análise do conjunto normativo da política educacional paulista que regulamenta a delegação de autonomia à rede de escolas, é possível verificar sua considerável distância do conceito de autonomia da perspectiva histórica, filosófica e política, e sua utilização como panacéia para os problemas que afetam a educação no estado de São Paulo. Fica evidente a ênfase na ampliação da autonomia nas questões pedagógicas. Porém, não parece novidade o fato de as escolas terem liberdade para dar o tratamento que acham mais conveniente aos conteúdos curriculares, pois pesquisas realizadas no espaço escolar indicam que, no limite, os educadores (re)significam as orientaçôes curriculares e imprimem uma prática particular às atividades de sala de aula, tanto no que tange aos métodos didáticos quanto no que diz respeito à avaliação de alunos. A possível substituição da normatização pedagógica, exercida fortemente no momento histórico anterior (anos de 1970), pela delegação de autonomia à escola, no que tange à elaboração de seus próprios projetos pedagógicos, seus conteúdos, metodologias e recursos didáticos, fica explicitada nas diretrizes oficiais e medidas legais. Porém os documentos também esclarecem que, com relação às questôes financeiras, a liberdade outorgada (entendida como autonomia) não ultrapassa o limite de buscar parcerias no setor privado, utilizando-se da APM para assinatura de convênios. 
A utilização do conceito de descentralização como sinônimo de desconcentração também fica evidente. Como se discutiu anteriormente, a desconcentração de medidas administrativas não significa descentralização, pois não foram desconstruídas as estruturas consolidadas no desenho institucional da Secretaria de Estado da Educação. Descentralizar significa transferir competências de decisão, cujo processo transformaria as estruturas e a dinâmica de exercício do poder. A implementação das recentes diretrizes oficiais da educação paulista, ao que tudo indica, não compartilhou o poder, mas, sim, transferiu responsabilidades administrativas.

Um avanço significativo pode ser considerada a medida legal que regulamenta o processo de escolha para designação de professor para exercer as funções de coordenação pedagógica nas escolas da rede pública estadual, pois esta atividade é de primordial importância na concatenação de um possível projeto pedagógico autônomo da escola. Outra conquista - o processo de regulamentação das funçôes de vice-diretor das escolas pelo Plano de Carreira pode ser vista da mesma perspectiva. A escolha de profissionais advindos do quadro do magistério para funções de gestão constitui a possibilidade de formação de uma equipe de direção que - aliada aos órgãos colegiados da unidade escolar - pode instaurar uma dinâmica mais democrática em seu funcionamento. Outro avanço se deu com a alteração da nomenclatura e a reorganização das Delegacias de Ensino, objetivando tornar mais ágil seu fluxo de atendimento, modernizar e racionalizar a Secretaria de Educação, bem como acelerar as medidas de descentralização para fortalecer a gestão local. $\mathrm{Na}$ realidade, essa medida também atendeu aos reclamos históricos do magistério, que sempre pontuaram os equívocos da estrutura e da nomenclatura das Delegacias de Ensino, constituindo um avanço com relação às mudanças necessárias no funcionamento burocrático da instituição.

Porém, permanecem os equívocos em torno do conceito de autonomia e de seus usos. ${ }^{15}$ Compreendendo-se seu exercício como prática e relação social, a concessão de autonomia parece se consolidar como delegação de normas e procedimentos a serem cumpridos, bem distante da noção de autonomia construída. Novidade seria se a legislação indicasse a possibilidade de exercício efetivo de autonomia das escolas, respeitando o conceito da perspectiva filosófica e política. Dessa forma, o conjunto normativo deveria preconizar a instauração de conselhos gestores com mandato revogável; a liber- 
dade das escolas para gerenciar recursos próprios e aplicá-los em suas prioridades; a possibilidade de elaborar suas normas regimentais, a partir de um documento norteador da organização políticopedagógica da rede de escolas; a ampliação dos procedimentos da avaliação externa realizada sobre a rede de escolas, incluindo-se procedimentos de auto-avaliação.

No entanto, na teoria e tampouco na prática não é isso o que vem ocorrendo, pois tanto as medidas legais quanto as orientações normativas que as implementam constituem uma ambigüidade: ao mesmo tempo que incentivam o exercício da autonomia escolar para elaboração coletiva de seu projeto pedagógico, estabelecem rigorosos procedimentos de organização e funcionamento das escolas, e ampliam sua vulnerabilidade financeira e de recursos físicos e humanos. A idéia mágica de que bastam novas normas para que a realidade se transforme, via de regra, tem constituído o cerne da política educacional paulista. Registre-se, no entanto, que os momentos de ruptura com as normas antigas e de instauração de novos procedimentos são extremamente saudáveis do ponto de vista institucional, pois garantem a desacomodação de valores organizacionais.

A avaliação externa realizada sobre o desempenho das escolas - a despeito de sua legitimidade como prerrogativa política de aferição dos usos feitos dos recursos públicos - parece não captar essa complexidade e tampouco suas características qualitativas, isto é, sua cultura, seus valores, a interação e os conflitos entre os pares e entre estes e a comunidade. Mesmo que seja mantida, essa prerrogativa deve ser reorientada e utilizada conjuntamente com outros procedimentos institucionais complementares, que permitam a instauração de mecanismos democráticos de desenvolvimento da autonomia escolar, pois criaria imensas possibilidades internas de reflexão sobre a prática profissional dos atores envolvidos.

\section{Recebido em fevereiro de 2003 e aprovado em março de 2003.}

\section{Notas}

1. As referências às medidas legais estão baseadas no conjunto de decretos, leis, resoluçôes e portarias publicados no compêndio de legislação sob responsabilidade da Coordenadoria de Estudos e Normas Pedagógicas da Secretaria de Estado da Educação de São Paulo, no período em pauta. A análise desse conjunto legal constitui parte de avaliação realizada sobre a política educacional paulista, defendida como tese de doutorado na Faculdade de Educação da Universidade Estadual de Campinas (UNICAMP). Neste texto, serão citados 
apenas alguns dos documentos oficiais analisados. As referências completas de legislação podem ser encontradas no referido estudo (Martins, 2001).

2. O conceito de autonomia está relacionado, na literatura sociológica e pedagógica, à noção de autogestão dos movimentos sociais de trabalhadores e das organizaçóes. Para que sejam ampliadas as possibilidades de seu exercício e desenvolvimento, os autores que fundamentaram a noção de pedagogia institucional, por exemplo, indicaram a auto-análise como um dos principais mecanismos de democratização da gestão das instituições de ensino (Lobrot, 1966). Na literatura sociológica, a autonomia das organizaçôes está diretamente relacionada à idéia de formação de conselhos gestores com mandato revogável.

3. Entre 1987-1991, medidas administrativas mais contundentes foram implementadas sob a justificativa de acelerar o processo de descentralização e autonomia do sistema de ensino e da rede de escolas: a contratação de pessoal administrativo, por meio do Programa de Municipalização e Descentralização do Pessoal de Apoio Administrativo das Escolas da Rede Pública Estadual (PROMDEPAR), e a contratação, via iniciativa privada, por intermédio do Banespa S.A. Serviços Técnicos e Administrativos (BANESER).

4. O Plano Executivo de 1987 e o Plano de Aplicação Qese de 1988 - peças importantíssimas na elaboração das diretrizes político-orçamentárias da secretaria estadual - insistiam no eixo da descentralização, utilizando-o, em alguns trechos, como sinônimo de autonomia para enfrentar os problemas vivenciados pelas escolas na tentativa de diminuir seu isolamento dos órgáos centrais e intermediários, bem como para reorientar os procedimentos normativos do Plano de Trabalho Anual/PTA, instrumento norteador do fluxo burocrático-financeiro e administrativo da área (São Paulo, 1987; 1988). Ambos os documentos responsabilizavam o sistema - entidade abstrata - pela pouca eficiência na conquista do sucesso de implantação dos programas de reforma propostos, pois os procedimentos normativos para elaboração do planejamento na área eram apontados como os maiores responsáveis pela excessiva centralização de recursos e de decisões administrativas.

5. Estrategicamente, em âmbito nacional, os governadores procuravam criar municípios pequenos, pois são mais fáceis de controlar e proporcionam o espaço físico para o estabelecimento dos redutos eleitorais dos deputados situacionistas. Dos 500 municípios criados entre 1980 e 1990,338 - 67\% do total - tinham entre 5 e 20 mil habitantes (...). Da Constituição de 1988 até 1995, foram criados 1.248 novos municípios (Abrucio, 1998).

6. Sobre o conceito de descentralização, ver Martins (2001). No referido artigo discutiu-se o uso instrumental do conceito de descentralização que, via de regra, vem sendo utilizado como sinônimo de desconcentração e, recentemente, como outorga de autonomia à unidade escolar. Buscou-se desenhar um breve painel sobre as complexas questôes que envolvem os processos descentralizadores, visando a iluminar as possíveis relaçóes entre as recentes diretrizes internacionais para as políticas educativas - invariavelmente gestadas no seio de organismos sediados em países desenvolvidos - e políticas de descentralização levadas a efeito em países periféricos.

7. O estado de São Paulo não é exceção no conjunto das demais unidades federadas, no que tange à repartição dos recursos nacionais e à distribuição desequilibrada de encargos, pois a redemocratização representou uma ruptura com o padrão financeiro das relações intergovernamentais estabelecido no período autoritário. Após as eleiçōes de 1982, a reforma tributária Passos Porto de 1983 (que elevou a participação de estados e municípios nos Fundos de Participação) deu início a um período de mudanças na distribuição de recursos tributários. É interessante salientar que, no período de 1980 a 1990, a importância relativa da União na receita disponível total das três esferas de governo caiu $17 \%$. Os estados e municípios tiveram um aumento de $26 \%$ e $70 \%$, respectivamente (Giambiagi, apud Abrucio, 1998).

Educ. Soc., Campinas, vol. 24, n. 83, p. 527-549, agosto 2003

Disponível em <http://www.cedes.unicamp.br> 
8. A título de exemplo, durante a gestão Fleury, a Assembléia Legislativa contava com 32 deputados da situação $(38 \%)$ do interior, contra 24 (28\%) da capital. A oposição contava com $19(23 \%)$ deputados da capital, contra apenas 9 (11\%) do interior.

9. Em avaliação realizada em 1992, porém, a própria secretaria reconhecia que os objetivos formulados para o programa eram extremamente gerais, não incentivando e sequer estimulando a criação de formas participativas para a escola e a comunidade assistida. Neste sentido, o documento de avaliação reconhecia, ainda, que o programa não permitia o salto de qualidade esperado na sua implementação, em virtude da impossibilidade de transferência mecânica de diretrizes teóricas, construídas pelos órgãos gestores, para as dimensões constitutivas de uma ação pedagógica participativa e integrada, "pensada como atendimento educacional integral à criança, sem que viessem à tona velhas fórmulas clientelistas $\mathrm{e}$ paternalistas", pois a Resolução n. 71 permitia a remoção do professor para a proximidade de sua residência, via Profic. O texto concluía destacando que a adesão dos municípios ao programa havia ocorrido de forma heterogênea e contraditória em face dos intervenientes financeiros, cujos fluxos são morosos e tendem a deixar as esferas locais, com menor poder de arrecadação, em situação difícil (São Paulo, 1992a).

10. Algumas dessas questôes foram discutidas de forma modificada em Martins (2002).

11. Ver, a esse respeito, artigo de Rezende (1990) sobre a emblemática questão da centralização versus descentralização, posta pela constituição da nação brasileira desde a instalação da Assembléia Constituinte em 1823, a partir da qual o apelo à federação passa a ser constante na história política brasileira. Os momentos políticos de intensa crise, que, via de regra, geram intensas negociações político-institucionais - a Regência, o Segundo Império, a Revolução de 30, entre outros -, desencadearam processos que promoveram mudanças na gestão do Estado, todas elas centradas no dilema da centralização/descentralização.

12. À época da campanha para governador, em 1998, Covas contava com $40 \%$ de aprovação de sua gestão, alcançando em menos de um mês (de 28/8/98 a 14/9/98) o segundo colocado, Francisco Rossi, ultrapassando-o logo em seguida. Segundo a imprensa, a ascensão do governador licenciado nas intenções de voto deveu-se, sobretudo, à propaganda eleitoral centrada na austeridade de sua administração e na realização de obras absolutamente necessárias. Acrescente-se que a imprensa deu muita atenção às medidas políticas da área de educação (Lima, 1998).

13. Segundo a própria Secretaria, no primeiro semestre de 1995, 384 prefeituras interessaram-se em participar do Programa de Parceria. Porém, os municípios não tinham idéia do que significava administrar uma rede maior, com todos os problemas decorrentes dessa situação. Os prefeitos reuniram-se com a Equipe de Municipalização da SEESP, quando ficaram evidenciados os intervenientes: os municípios estavam habituados a gerenciar uma rede de pré-escolas e a utilizar os excedentes da verba em educação com merenda, construção de quadras esportivas e transporte de alunos de todos os níveis, inclusive universitários. Constatada essa situação, os prefeitos interessados participaram de dez encontros técnicos com a equipe central da secretaria para assumir as novas responsabilidades administrativas e financeiras (São Paulo, 2002).

14. Em pesquisa de campo realizada no estudo citado anteriormente, foi possível observar que a equipe de direção, diante da amplitude das demandas para que a escola cumpra um conjunto normativo e legal cada vez maior, buscou soluçóes singulares para resolver problemas administrativos, financeiros e pedagógicos, sublinhando o acúmulo de trabalho administrativo advindo de fatores endógenos (institucionais; mudanças de procedimentos administrativos) e de fatores exógenos (ampliação de contatos com a comunidade escolar).

15. Na referida tese de doutorado tomou-se como referência filosófica a noção de autonomia em Castoriadis. O pensador considera que na história mais recente da humanidade constituiu-se uma tensão entre os movimentos autônomos e o conjunto de instituições sociais 
cuja função tem sido a de garantir a reprodução das relações sociais de produção, a partir sobretudo do advento da sociedade capitalista. Neste sentido, as possibilidades e os limites para o exercício da autonomia são dados, historicamente, por um conjunto de fatores subjetivos. Ela só pode ser definida, portanto, como relação social, pois “(...) não podemos desejar a autonomia sem desejá-la para todos e sua realização só pode conceber-se como empreitada coletiva. Se não se trata mais de entender por esse termo nem a liberdade inalienável de um sujeito abstrato, nem o domínio de uma pura consciência sobre um material indiferençado para todos (...); se o problema da autonomia é que o sujeito encontra em si próprio um sentido que não é o seu e que tem que transformá-lo utilizandoo; se a autonomia é essa relação na qual os outros estão sempre presentes como alteridade (...), então a autonomia só é concebível, já filosoficamente, como um problema e uma relação social" (Castoriadis, 1991, p. 130).

\section{Referências bibliográficas}

ABRUCIO, F.L. O ultrapresidencialismo estadual. In: ANDRADE, R.C. (Org.). Processo de governo no Município e no Estado. São Paulo: EDUSP/FAPESP, 1998. p. 87-117.

AZANHA, J.M.P. Autonomia da escola: um reexame. Idéias, São Paulo, n. 16, p. 37-46, 1993.

AZANHA, J.M.P. Educação, alguns escritos. São Paulo, Nacional, 1987.

CASTORIADIS, C. A instituição imaginária da sociedade. Rio de Janeiro: Paz \& Terra, 1991.

COSTA, V.M.F.; OLIVEIRA, C.T.C. A fraqueza da Assembléia Legislativa do Estado de São Paulo. In: Andrade, R.C. (Org.). Processo de governo no município e no estado. São Paulo: EDUSP/FAPESP, 1998. p. 117-147.

FLETCHER, P.R.; CASTRO, C.M. Mitos, estratégias e prioridades para o ensino de $1^{\circ}$ grau. Estudos em Avaliação Educacional, São Paulo, n. 8, p.39-56, jul./dez. 1993.

GATTI, B.A. Desenvolvimento de projetos de avaliação do sistema educacional do Estado de São Paulo. Estudos em Avaliação Educacional, São Paulo, n. 13, p.19-26, jan./jun. 1996.

GIAMBIAGI apud ABRUCIO, F.L. O ultrapresidencialismo estadual. In: Andrade, R.C. (Org.). Processo de governo no município e no estado. São Paulo: EDUSP/FAPESP, 1998, p. 87-117.

LIMA, M. A reação do eleitor. Veja, São Paulo, n. 38, p. 42, 23 set. 1998.

Educ. Soc., Campinas, vol. 24, n. 83, p. 527-549, agosto 2003

Disponível em <http://www.cedes.unicamp.br> 
LOBROT, M. Pedagogia institucional: la escuela hacia la autogestión. Buenos Aires: Humanitas, 1966.

MARTINS, A.M.; ALVES, L.M. A municipalização do ensino e o Decreto 30.375/89. Revista ANDE, São Paulo, n. 16, p.26-29, 1990.

MARTINS, A.M. Autonomia e gestão da escola pública: entre a teoria e a prática. 2001. 306f. Tese (Doutorado) - Faculdade de Educação, Universidade Estadual de Campinas, Campinas.

MARTINS, A.M. A descentralização como eixo das reformas de ensino: uma discussão da literatura. Educação \& Sociedade, Campinas, n. 77, p. 28-29, dez. 2001.

MARTINS, A.M. Autonomia e gestão da escola pública: aportes para uma discussão. In: Oliveira, D.A.; Rosar, M.F.F. (Org.). Política e gestão da educação. Belo Horizonte: Autêntica, 2002. p. 105-124.

PEREIRA, L. A escola numa área metropolitana: crise e racionalização de uma empresa de serviços pública. São Paulo: Pioneira; EDUsP, 1967.

REZENDE, P. A República pela via da Federação. São Paulo em Perspectiva, São Paulo, v. 4, n. 1, p. 28-32, jan./mar. 1990.

RIBEIRO, S.C. A pedagogia da repetência. Estudos em Avaliação Educacional, São Paulo, n. 4, p. 73-86, jul./dez. 1991.

SILVA, T.R.N. Plano de metas da atual gestão da Secretaria de Estado da Educação de São Paulo e análise do perfil da Secretaria. Estudos em Avaliação Educacional, São Paulo, n. 13, p. 7-12, jan./jun. 1996.

SILVA, T.R.N. Descentralização da educação no estado de São Paulo. In: Costa, V.L.C. (Org.). Descentralização da educação: novas formas de coordenação e financiamento. São Paulo: FUndap; Cortez, 1999. p. $168-90$.

SÃO PAULO (Estado). Secretaria da Educação. Documento de reorientação das atividades da Secretaria de Estado da Educação. Diário Oficial do Estado, São Paulo, 07 jun. 1983. Supl. especial.

SÃO PAULO (Estado). Proposta de reforma administrativo-organizacional da Secretaria de Estado da Educação de São Paulo. São Paulo: FUNDAP, 1984. v. 1/3.

SÃO PAULO (Estado). Plano Executivo. São Paulo, 1987 
SÃO PAULO (Estado). Secretaria da Educação. Assessoria Técnica de Planejamento e Controle. Aplicação da verba QESE. São Paulo, 1988

SÃO PAULO (Estado). Secretaria da Educação. Banco Mundial. Projeto inovaçôes no ensino básico: ciclo básico; jornada única. São Paulo, 1989. v. 1-2.

SÃO PAULO (Estado). Secretaria da Educação. Coordenadoria de Estudos e Normas Pedagógicas. PROFIC: avaliação de um projeto. São Paulo, 1992a.

SÃO PAULO (Estado). Secretaria da Educação. Fundação para o Desenvolvimento da Educação. Programa de reforma da escola pública. São Paulo, 1992b.

SÃO PAULO (Estado). Secretaria da Educação. A escola que faz diferença. São Paulo, 1997. 1 v.

SÃO PAULO (Estado). Secretaria da Educação. A municipalização do ensino fundamental: o sucesso e o processo. São Paulo, 2002. 